\title{
Environmental Impact Assessment of Estuaries in Southeast Coast of India using Fish Health Index and Index for Biotic Integrity (IBI) for Fishes
}

\author{
Khan S.A.*, Lyla P.S. and Khadharsha K. \\ Centre of Advanced Study in Marine Biology, Annamalai University, India \\ *seyedajmal@gmail.com
}

\begin{abstract}
Estuaries are ecotones connecting terrestrial, freshwater and marine ecosystems. They are highly productive and act as detritus trap for both autochthonous and allochthonous materials. In view of their manifold uses, estuaries are under increasing threat from a wide range of natural and anthropogenic pressures, leading to an increasing emphasis on environmental impact assessment (EIA) and monitoring. Water quality index has been used globally in EIA. Of late the emphasis has shifted to the use of biotic elements in EIA. Among the various groups of organisms used for this purpose, fishes hold several advantages over other biota as the taxa of choice for EIA. As a consequence Fish Health Index (FHI) (Cooper et al., 1993) and Index for Biotic Integrity (IBI) (Karr, 1991) for fishes have been developed and are being used elsewhere. Therefore in the present study these indices were used for assessing the health of the environment in three estuaries namely Coleroon, Vellar and Uppanar.

A total of 104 species, belonging to 69 genera, 44 families and 10 orders were found to occur in the three estuaries. The numbers of fish species recorded in Coleroon, Vellar and Uppanar estuaries were 58, 91 and 22 respectively. The FHI which ranges from 0(Poor) to 10(Good) was found to be 9.33 for Vellar, 7.35 for Coleroon and 3.34 for Vellar. Thirteen metrics were used to develop the IBI and the index varied from 18(Uppanar) to 51(Vellar). Two-way ANOVA revealed significant differences in the metrics among the estuaries. Based on the IBI scores the environmental quality of Coleroon, Vellar and Uppanar was found to be 'Fair', 'Good' and 'Very poor'. As fishes can be collected and identified in the field itself, these indices are found to be quite advantageous for EIA than the other methods where organisms need to be collected and preserved before identification.
\end{abstract}

Keywords: EIA, Estuaries, Fishes, FHI, IBI

Proceedings of the International Forestry and Environment Symposium 2016, Department of Forestry and Environmental Science, University of Sri Jayewardenepura, Sri Lanka. 